\title{
Impact of Cobalt Doping on Structural, Electrical, Magnetic and Optical Properties of Zn1-xCoxO Nanocomposites: Experimental and Theoretical Study
}

Harish Kumar ( $\nabla$ harimoudgil1@gmail.com )

Department of Chemistry, Central University Haryana https://orcid.org/0000-0002-8559-2302

Ram Mehar Singh

Department of Physics, Ch. Devi Lal University

Ram Pal

Department of Physics, Ch. Devi Lal University

\section{Research Article}

Keywords: Nanocomposites, Spintronics, Transition metals, Sol-gel method, Computational study.

Posted Date: March 18th, 2021

DOl: https://doi.org/10.21203/rs.3.rs-309594/v1

License: (c) (1) This work is licensed under a Creative Commons Attribution 4.0 International License.

Read Full License 


\title{
Impact of cobalt doping on structural, electrical, magnetic and optical properties of $\mathrm{Zn}_{1-\mathrm{x}} \mathrm{Co}_{\mathrm{x}} \mathrm{O}$ nanocomposites: Experimental and theoretical study
}

\author{
Ram Mehar Singh', Ram Pal', Harish Kumar,"* \\ ${ }^{1}$ Department of Physics, Ch. Devi Lal University, Sirsa (Haryana) -125055 \\ ${ }^{2}$ Department of Chemistry, Central University Haryana, Mahendergarh-123031 \\ *Author for correspondence: harishkumar@cuh.ac.in
}

\begin{abstract}
Doping of nanocomposites (NCs) with different metal oxide leads to a significant change in its structural, optical, electrical, mechanical, thermal, catalytic, and magnetic properties. The effect of the addition of $\mathrm{CoO}$ nanoparticles (NPs) on the structural, optical, electrical, and magnetic properties of $\mathrm{Zn} / \mathrm{CoO} \mathrm{NCs}$ have been investigated in detail. $\mathrm{Zn}_{1-\mathrm{x}} \mathrm{Cox}_{\mathrm{x}} \mathrm{O}$ NCs were synthesized by the sol-gel method followed by annealing at $400^{\circ} \mathrm{C}$. The NCs were characterized by UV-visible, XRD, FTIR, TEM, and vibrating sample magnetometer (VSM) techniques. The structural and surface study was performed by X-ray diffraction and TEM techniques which shows spherical and cubical NCs with an average size of 25-55 $\mathrm{nm}$. Computational study (DMol3, CASTEP, Forcite, and Reflex) was used to study the electronic and optical properties of metal NPs. The $\mathrm{Co}^{2+}$ ions replace $\mathrm{Zn}^{2+}$ ions in the $\mathrm{ZnO}$ lattice resulting a change in its structure from Wurtzite ( $\mathrm{ZnO} N P s$ ) to cubic $\mathrm{Zn}_{1-\mathrm{x}} \mathrm{Co}_{\mathrm{x}} \mathrm{O}$ NCs. The lattice parameters, strain, and dislocation density were found to decrease with an increase in $\mathrm{CoO}$ concentration in $\mathrm{Zn}_{1-\mathrm{x}} \mathrm{Cox}_{\mathrm{x}} \mathrm{O}$ NCs. The saturation magnetization, retentivity, and coercivity were found to be lesser in $\mathrm{Zn}$ ${ }_{x} \mathrm{Co}_{x} \mathrm{O}$ NCs. The synthesized cobalt doped $\mathrm{Zn}_{1-\mathrm{x}} \mathrm{Co}_{\mathrm{x}} \mathrm{O}$ NCs can act as an efficient material for spintronic applications.
\end{abstract}

Keywords: Nanocomposites, Spintronics, Transition metals, Sol-gel method, Computational study. 


\section{Introduction}

The nanostructured materials have achieved special attention due to their novel properties. Controlling the dimensionality and morphology of materials have gained interest for designing functional devices having unique magnetic as well as optical properties. "The oxide semiconductors play a vital role in the area of photonic and spintronic. Recently, spintronics has drawn attention to make use of both spin and charge freedom of the carriers for the new devices. The spintronic is the emerging technology based on the concept of spin states (up and down) of electrons to carry the information that can be manipulated by an external applied magnetic field. The concept of spin helps in the designing of devices for high data processing, large integration capacity, reduced power consumption, and better stability. The transition metals doped semiconductors are useful in different research activities because of their usual optical properties and encouraging potential for applications in optoelectronic devices [1, 2]. Among these semiconductors, few efforts have been made for the doping of $\mathrm{ZnO}$ nanocrystals with cobalt ions to extend the application potential $[3,4]$. $\mathrm{ZnO}$ is one of the hopeful materials for low voltage and short-wavelength optoelectronic applications like UV devices, light-emitting diodes, gas sensors, and laser diodes" [5-9]. The transition metals doped nanostructure is effective to adjust the energy levels and surface states of $\mathrm{ZnO}$, which can introduce changes in structural and magnetic properties. In the present work, we have investigated the structural properties in cobalt doped $\mathrm{ZnO}$ nanocomposite prepared by a solgel technique which is a simple and low-temperature method, the possibility of making of finely dispersed powder and it yields a good end product. The synthesized samples are characterized by different techniques i.e., XRD, TEM, and UV-visible spectroscopy.

In continuation to our earlier work [10-13], here, we have reported the effect of cobalt NPs on the structural and optical properties of $\mathrm{Zn}_{1-\mathrm{x}} \mathrm{Co}_{\mathrm{x}} \mathrm{O}$ NCs. The $\mathrm{Zn}_{1-\mathrm{x}} \mathrm{Co}_{\mathrm{x}} \mathrm{O}(\mathrm{x}=0.3,0.5,0.7) \mathrm{NCs}$ were synthesized by sol-gel technique at $80 \square \mathrm{C}$ and annealed at temperatures $400{ }^{\circ} \mathrm{C}$ for $6 \mathrm{~h}$. The effect of $\mathrm{CoO}$ concentration on the structure of NCs was studied by FTIR, TEM, and XRD. The FTIR spectroscopy shows the presence of zinc oxide at different concentrations. The surface study was done by TEM and magnetic properties by VSM techniques. The theoretical (computational) study was carried out by Gaussian09 and Material Studio 2017 software by using density functional theory (DFT) theory. For the first time, both theoretical and experimental study was carried out to explain the effect of $\mathrm{CoO}$ concentration on the structure of $\mathrm{Zn}_{1-\mathrm{x}} \mathrm{Cox} \mathrm{O}$ NCs. 


\section{Experimental}

\section{Sample Preparation}

Pure $\mathrm{ZnO}, \mathrm{CoO}$, and $\mathrm{Zn}-\mathrm{CoO} \mathrm{NCs}$ were synthesized by using the sol-gel technique. $\mathrm{C}_{4} \mathrm{H}_{6} \mathrm{O}_{4} \mathrm{Zn} .2 \mathrm{H}_{2} \mathrm{O}$ was used as a precursor of the $\mathrm{ZnO}$ NPs and cobalt chloride hexahydrate $\left(\mathrm{CoCl}_{2} .6 \mathrm{H}_{2} \mathrm{O}\right)$ is used as a precursor of the $\mathrm{CoO} N P$. For synthesizing $\mathrm{Zn}_{1-\mathrm{x}} \mathrm{Co}_{\mathrm{x}} \mathrm{O}(\mathrm{x}=0,0.3$, $0.5,0.7,1)$ by sol-gel method, two solutions A and B were prepared. The solution 'A' was prepared by an aqueous solution of $x \mathrm{M} \mathrm{CoCl}_{2} .6 \mathrm{H}_{2} \mathrm{O}$ and (1-x) $\mathrm{M}_{4} \mathrm{H}_{6} \mathrm{O}_{4} \mathrm{Zn} .2 \mathrm{H}_{2} \mathrm{O}$ acidified with few drops of concentration $\mathrm{HNO}_{3}$ to maintain the $\mathrm{pH}=3$. The solution ' $\mathrm{B}$ ' was prepared by mixing TEOS and ethanol in a molar ratio of 1:4, respectively. Now, solution A was mixed to solution B dropwise with continuous stirring at room temperature. The solution was then heated at $80 \square \mathrm{C}$ with constant stirring in a closed container for $6 \mathrm{~h}$. The sol prepared was transferred to the previously sterilized Petri plates $(22 \mathrm{~mm})$ and kept in an oven sustained at a temperature of 100 C. It was observed that gelation appeared after $24 \mathrm{~h}$. Even after gelation, the sample was still kept inside the oven for few hours for further aging. The aging process allows further shrinkage and stiffening of the gel. After complete gelation, the sample was annealed at $400 \square$ for $4 \mathrm{~h}$. The proposed chemical reaction during the doping process are as under:

$$
\begin{aligned}
& (1-x) \mathrm{C}_{4} \mathrm{H}_{6} \mathrm{O}_{4} \mathrm{Zn} .2 \mathrm{H}_{2} \mathrm{O}+x \mathrm{CoCl}_{2} \cdot 6 \mathrm{H}_{2} \mathrm{O}+2 \mathrm{C}_{2} \mathrm{H}_{5} \mathrm{OH} \rightarrow\left(\mathrm{C}_{2} \mathrm{H}_{5} \mathrm{O}\right)_{2} Z_{(1-x)} \mathrm{Co}_{x}+ \\
& 2(1-x) \mathrm{CH}_{3} \mathrm{COOH}+2 x \mathrm{HCl}+8 x \mathrm{H}_{2} \mathrm{O} \\
& \left(\mathrm{C}_{2} \mathrm{H}_{5} \mathrm{O}\right)_{2} \mathrm{Zn}_{(1-x)} \mathrm{Co}_{x}+2 \mathrm{H}_{2} \mathrm{O} \stackrel{H^{+}}{\rightarrow} \mathrm{Zn}_{(1-x)} \mathrm{Co}_{x}(\mathrm{OH})_{2}+2 \mathrm{C}_{2} \mathrm{H}_{5} \mathrm{OH} \\
& Z n_{(1-x)} C o_{x}(\mathrm{OH})_{2} \stackrel{\Delta}{\rightarrow} Z n_{(1-x)} C o_{x} \mathrm{O}+\mathrm{H}_{2} \mathrm{O}
\end{aligned}
$$

Characterization of sample

The characterization of the $\mathrm{Zn}_{\mathrm{x}} \mathrm{CoO}_{1-\mathrm{x}} \mathrm{NCs}$ was carried out to know the crystalline size and lattice constant. XRD spectra were recorded in the X-ray diffractometer (Philip PW/1710), Cu K $\alpha$ with wavelength $1.548 \AA$ at $50 \mathrm{kV}$ and $40 \mathrm{~mA}$ scanned from 10 to $90^{\circ}$. TEM images were taken for different NCs (Hitachi-H7500) at $100 \mathrm{kV}$. The FTIR spectra of different NCs were recorded (Perkin Elmer 1600). The VSM (micro sense E29) was used to study the magnetic properties (M-H curve) at room temperature.

\section{Computational study}

The theoretical study of synthesized metal oxide NPs was carried out by Material Studio 2017, USA software. The electronic and optical properties were studied by geometry optimization, energy, energy density, frequency, and orbital studies by DMol3, CASTEP, Forcite, and Reflex modules. Fig. 11 and 12 shows DMol3 density of states (DOS), Forcite radial distribution 
function (RDF), Forcite X-ray intensity versus $2 \square$ (XRD), CASTEP band structure, CASTEP density of states (DOS), and 3D molecular crystal structure depicting reciprocal lattice and Brillouin zone paths of $\mathrm{ZnO}$ and CoO NPs obtained from Materials Studio 2017 software. Fig. 11 shows CASTEP band structure, CASTEP density of states (DOS), Forcite X-ray intensity versus $2 \square$ (XRD), Forcite radial distribution function (RDF), XRD, the spatial distribution of atoms, and 3D molecular structure showing reciprocal lattice and Brillouin zone paths of $\mathrm{ZnO}$ NPs. Fig. 12 shows CASTEP band structure, DMol3 DOS, Forcite radial distribution function (RDF), XRD, 3D crystal structure, spatial distribution of atoms, and 3D molecular structure showing reciprocal lattice and Brillouin zone paths of CoO NPs.

\section{Results and discussion}

The $\mathrm{Zn}_{1-\mathrm{x}} \mathrm{Co}_{\mathrm{x}} \mathrm{O} \mathrm{NCs}$ with different ratio of cobalt as dopant material $(\mathrm{x}=0,0.3,0.5,0.7,1)$ were synthesized. The characterization of NCs was performed by XRD, FTIR, VSM, and TEM techniques.

\section{XRD study}

Fig. 1(a) shows that the X-ray diffraction pattern of $\mathrm{ZnO}$ NPs annealed at $400 \mathrm{C}$. The peaks are identified as $2 \theta=31.84,34.56,36.24,47.6,56.64,62.96$, and 68.08 which are indexed at (100), (002), (101), (102), (110), (103) and (112) crystal planes, respectively and corresponding inter planner spacing 2.81, 2.59, 2.47, 1.91, 1.62, 1.47 and $1.37 \AA$, respectively. The diffraction peaks correspond to the hexagonal wurtzite crystal structure of zinc oxide [14-16] with lattice parameters $\mathrm{a}=\mathrm{b}=3.24 \AA$, $\mathrm{c}=5.18 \AA$. The indexing pattern matches with JCPDS card 800075 .

The grain size of ZnO NPs was determined by Debye -Scherrer's formula (Eq. 1) [17].

$$
D=\frac{\mathrm{k} \lambda}{\beta \cos \theta}
$$

The lattice parameters of hexagonal lattice were calculated by using Eq. (2).

$$
\frac{1}{d^{2}}=\frac{4}{3}\left[\frac{h^{2}+h k+k^{2}}{a^{2}}\right]+\frac{l^{2}}{c^{2}}
$$

The lattice parameters of cubic lattice were calculated by using Eq. (3).

$$
\frac{1}{d^{2}}=\left[\frac{h^{2}+k^{2}+l^{2}}{a^{2}}\right]
$$

The dislocation density $(\delta)$ was calculated from the crystalline size (D) using Williamson and Hall relationship Eq. (4) [18].

$$
\delta=\frac{1}{D^{2}} \quad\left(\mathrm{~nm}^{-2}\right)
$$


The micro strain broadening and crystallite size were calculated from the W-H relationship Eq. (5).

$$
\beta \cos \theta=\frac{\mathrm{k} \lambda}{\mathrm{D}}+4 \epsilon \sin \theta
$$

The average size of ZnO NPs as observed from XRD was $20.91 \mathrm{~nm}$. The interplanar spacing was $2.47 \AA$ and the dislocation density obtained from Eq. (4) was $1.45 \times 10^{-3} \mathrm{~nm}^{-2}$

For the determination of the crystallite size and strain contribution to the peak broadening, a graph is plotted between $\beta \cos \theta$ and $4 \operatorname{Sin} \theta$ according to W-H eq. (5) shown in Fig. 1(b). A straight line was obtained with a slope equal to the strain and intercept equal to crystallite size. The average size from the $\mathrm{W}-\mathrm{H}$ plot was $17.56 \mathrm{~nm}$ and the corresponding lattice strain was 0.0053 .

Fig. 2(a) shows the XRD pattern of CoO NPs. The peaks are indexed at angle 2 $\theta: 18.64,25.52$, $30.8,33.2,35.2,38.88,41.12,43.76,45.92,48.08,52.0,54.0,55.84,59.68,65.52$ and 74.56 . The crystal size corresponding to the highest intensity peak was $26.19 \mathrm{~nm}$ and the corresponding lattice strain was 0.00042. Fig. 2(a) shows some extra and faint reflections which may be due to the traces of $\mathrm{Co}(\mathrm{OH})_{2}$ and are marked as impurities [19].

To calculate the size and strain contribution to the peak broadening in the lattice, a graph was plotted between $\beta \cos \theta$ and $4 \sin \theta$ according to W-H Eq. (5) shown in Fig. 2(b). A straight line was obtained with a slope corresponding to strain and intercept to crystallite size. The average crystallite size from the W-H plot was $20.92 \mathrm{~nm}$ and the corresponding lattice strain was 0.0042 . Fig. 3 shows the XRD pattern of $\mathrm{Zn}_{1-\mathrm{x}} \mathrm{OCo} \mathrm{O}_{\mathrm{x}} \mathrm{O}$ NCs. The peaks at $2 \theta$ angle of 30.71 , $36.24,44.0,58.74$, and 64.52 were indexed at (220), (311), (400), (511), and (440) crystal planes, respectively. The diffraction peaks correspond to the cubic crystal structure and no other secondary and impurity phase was detected [20]. The intensity of the peaks was increased and peak width decreases with an increase in the concentration of $\mathrm{CoO}$ dopant in $\mathrm{Zn}-\mathrm{CoO} \mathrm{NCs}$ as $\mathrm{ZnO}$ and $\mathrm{CoO}$ fuse together and as a result whole of the crystallite size increases. The crystalline size of the different NPs and NCs was determined and is shown in Table 1. The particle size increases linearly with an increase in the concentration of $\mathrm{CoO}$ in the NCs. The enlargement of the NCs was due to grain growth as $\mathrm{ZnO}$ and $\mathrm{CoO}$ NPs merge. All the diffraction peaks agreed to JCPDS card no. 78-0643. Additional peaks represent the secondary phase of $\mathrm{CoO}$ were calculated for $\mathrm{x}=0.3,05,0.7$ at $400 \square \mathrm{C}$. The mixing of $\mathrm{CoO}$ changes the Wurtzite structure of NPs of $\mathrm{ZnO}$ into the cubic structure of $\mathrm{Zn}-\mathrm{CoO}$ NCs. 
The W-H study was employed to know the individual contribution of crystallite size and lattice strain on the peak broadening of cobalt doped ZnO NCs. The Williamson-Hall (W-H) plots shows isotropic line broadening (Fig. 4). The diffracting domains were observed to be isotropic and there was a micro strain contribution. The particle size of pure and doped ZnO NPs was found by Debye-Scherrer and W-H plot. Both Scherrer and W-H analysis confirms that the particle size of Co-doped $\mathrm{ZnO}$ NCs increases with cobalt concentration. The size of Co-doped $\mathrm{ZnO}$ NCs calculated by the W-H plot was found to be greater than the Scherrer method. Using the Scherrer formula (Eq. 1), the crystalline size for undoped $\mathrm{ZnO}$ was $20.91 \mathrm{~nm}$, and for $\mathrm{x}=$ 0.3 , the size was $14.93 \mathrm{~nm}$. The $\mathrm{Co}^{+2}$ ion prevents the nucleation and growth of the NCs [15]. For $\mathrm{x}=0.5$ and 0.7 , the crystallite size was 19.21 and $23.28 \mathrm{~nm}$, respectively. X-ray diffraction study reveals that $\mathrm{ZnO}$ loaded with $\mathrm{CoO}$ has a single-phase Wurtzite structure and no secondary phase was detected indicating that $\mathrm{Co}^{2+}$ ions were effectively entered into the lattice of $\mathrm{Zn}^{2+}$ ions. To know the effect of cobalt concentration, a vigilant exploration of the position of the XRD peaks indicates a shift in the peak's position to a lower $2 \theta$ value with increasing Co concentration. "The shifting of the peak's position indicates that the lattice parameters increases with Co concentration. The lattice parameters increase Co concentration which shows that $\mathrm{Co}$ ions are replacing $\mathrm{Zn}$ in $\mathrm{ZnO}$ matrix and these results are in good agreement with literature" [21]. The crystalline size increases, the lattice strain and the dislocation density decrease with an increase in Co concentration in the NCs.

The lattice parameters decrease slightly with an increase in $\mathrm{CoO}$ concentration in the NCs. The $\mathrm{Co}^{+2}$ ions (small radii) replaces $\mathrm{Zn}^{+2}$ in the $\mathrm{ZnO}$ crystal lattice and interstitial sites with a cubic crystal structure. The lattice parameters were calculated using the X-ray diffraction method for all the NCs [22]. The corresponding lattice parameters were tabulated in Table 1. The lattice parameters of the nanocomposite do not change significantly with an increase in $\mathrm{CoO}$ concentration, which shows that $\mathrm{Co}^{2+}(0.58 \AA)$ and $\mathrm{Zn}^{2+}(0.6 \AA)$ have almost identical radii [23].

\section{FTIR spectra}

The FTIR spectroscopy was used to find the purity and nature of NPs and NCs. The infrared spectra of $\mathrm{Zn}_{1-\mathrm{x}} \mathrm{Co}_{\mathrm{x}} \mathrm{O}$ ( $\mathrm{x}=0,0.3,0.5,0.7$, and 1) were used to provide the information of absorption bands to specific vibrational mode. Fig. 5(a) depicts the FTIR spectra of the ZnO NPs. The absorption peak at $3325 \mathrm{~cm}^{-1}$ corresponds to $\mathrm{O}-\mathrm{H}$ stretching. The peak at $2856 \mathrm{~cm}^{-1}$ represents $\mathrm{O}=\mathrm{C}=\mathrm{O}$ stretching vibration of $\mathrm{CO}_{2}$. The absorption peak around 1793 and 1856 
$\mathrm{cm}^{-1}$ are due to $\mathrm{H}-\mathrm{O}-\mathrm{H}$ bending vibration. The peak at $1462 \mathrm{~cm}^{-1}$ shows bending vibration of $\mathrm{C}=\mathrm{O}$ stretching $[24,25]$. The $\mathrm{Zn}-\mathrm{O}$ and $\mathrm{Co}-\mathrm{O}$ stretching vibrations were seen at $500-1000 \mathrm{~cm}^{-}$ 1. Fig. 5(b) shows the FTIR spectra of the CoO powder in the range of $4000-500 \mathrm{~cm}^{-1}$. The absorption peak at $1756 \mathrm{~cm}^{-1}$ is due to the $\mathrm{OH}$ group in the metal alkoxides present in the gel and $1612 \mathrm{~cm}^{-1}$ shows bending vibration of $\mathrm{H}_{2} \mathrm{O}$. The absorption peak at $1081,806,768 \mathrm{~cm}^{-1}$ stands for C-O stretching in presence of phosphine oxide. The peak at $567 \mathrm{~cm}^{-1}$ [26] was due to Co-O stretching and at $660 \mathrm{~cm}^{-1}$ corresponds to bridging $\mathrm{O}-\mathrm{Co}-\mathrm{O}$ bond [27].

Fig. 6 shows the FTIR spectra of $\mathrm{Zn}_{1-\mathrm{x}} \mathrm{Co} \mathrm{x}(\mathrm{x}=0.3,0.5,0.7)$ NCs in the range of 4000- 500 $\mathrm{cm}^{-1}$. The absorption peak at $3480 \mathrm{~cm}^{-1}$ was due to the $\mathrm{O}-\mathrm{H}$ stretching vibration. The peak at 2728,1759 , and $1625 \mathrm{~cm}^{-1}$ shows bending vibration of water, and the peak at $1631 \mathrm{~cm}^{-1}$ represents $\mathrm{C}-\mathrm{H}$ stretching vibration. The absorption peak at $1416 \mathrm{~cm}^{-1}$ is due to the C-O absorption of the $\mathrm{ZnO}$ surface. The region $1043-612 \mathrm{~cm}^{-1}$ is due to the influence of Co in the spectra of Zn-CoO NCs [28, 29]. The very small peaks were seen at 819,741 , and $613 \mathrm{~cm}^{-1}$ corresponding to $\mathrm{O}-\mathrm{C}=\mathrm{O}$ formation (Table 2). An increase in the concentration of $\mathrm{CoO}$, the frequency of absorption swing towards lower wavenumber (redshift). A shift in the $\mathrm{ZnO}$ peak reveals that the $\mathrm{ZnO}$ NCs network was distressed by the addition of $\mathrm{CoO}$. The FTIR study indicates that $\mathrm{Co}$ is replacing $\mathrm{Zn}$ atoms from the lattice site in the NCs matrix and the same was supported by XRD.

\section{TEM study}

Fig. 7 shows the TEM images of the nanocrystalline nature of zinc oxide, cobalt oxide, and zinc- cobalt oxide NCs. TEM images of zinc oxide show aggregates of smooth and nonuniform solids of different shapes and sizes in the range 20-94 $\mathrm{nm}$ and cobalt oxide showed aggregates of smooth nanocrystals of different shapes and sizes in the range $23-97 \mathrm{~nm}$.

Fig. 8 shows the TEM image of zinc-cobalt oxide NCs. The ZnO NPs show the process of agglomeration during their synthesis. The TEM image reveals the compact arrangement of homogenous NPs with almost spherical, quasi-spherical, and core-shell structures showing the crystalline nature of the metal oxide and small coarse grains representing the presence of the amorphous structure of silica. The particle size of the NCs was found to increase with an increase in the concentration of CoO NPs. The TEM image indicates the formation of NPs cluster which was due to the magnetic dipole interaction between the ZnO NPs. The particle size was found to in the range of 25-55, 24-66 and 28-47 $\mathrm{nm}$ for $\mathrm{x}=0.3,0.5$ and 0.7 , 
respectively. A close agreement in particle size was observed from TEM and XRD techniques. TEM image confirms that $\mathrm{ZnO}$ and $\mathrm{CoO}$ NPs fuse to increase the NCs size and volume.

Vibrating Sample Magnetometer (VSM) study

The magnetic properties of NPs and NCs of $\mathrm{ZnO}, \mathrm{CoO}$, and $\mathrm{Zn}_{0.3}-\mathrm{CoO}_{0.7}$ was studied VSM technique in the range of -10 to $10 \mathrm{k}$ Oe (Fig. 9). Fig. 9 shows the hysteresis curve of different metal NPs and their NCs. All the NCs show hard ferromagnetic behavior at room temperature. The diamagnetic component was subtracted from the original data to determine the ferromagnetic part. The value of magnetic remanence $\left(M_{r}\right)$ and Coercivity $\left(H_{c}\right)$ of $\mathrm{ZnO}, \mathrm{CoO}$, and $\mathrm{Zn}-\mathrm{CoO}$ NCs were shown in Table 2 . The coercivity $\left(H_{c}\right)$ increases and remanence $\left(\mathrm{M}_{\mathrm{r}}\right)$ decreases with the addition of $\mathrm{CoO}$ NPs in ZnO NPs. The presence of ferromagnetic behavior in NCs was due to intrinsic coupling between the magnetic dipoles [30, 31]. The possibility of ferromagnetic behavior in the NCs was due to the formation of metallic clusters and secondary phases due to traces of $\mathrm{Co}(\mathrm{OH})_{2}$ impurities.

The VSM shows that the ferromagnetic behavior of synthesized NCs decreases at room temperature. The $\mathrm{CoO}$ form clusters rather than substituting the $\mathrm{Zn}$ lattice sites. At higher $\mathrm{CoO}$ concentration, the possibility of the formation of $\mathrm{CoO}$ clusters increases.

\section{UV-visible absorption study}

To study the optical and electrical properties of $\mathrm{CoO} / \mathrm{ZnO} \mathrm{NCs}$, a UV-visible absorption study was carried out for $\mathrm{ZnO}, \mathrm{CuO} \mathrm{NPs}$, and $\mathrm{CoO} / \mathrm{ZnO}$ NCs. Fig. 10 depicts UV-visible spectra of $\mathrm{CoO}, \mathrm{ZnO}$ NPs, and $\mathrm{ZnO} / \mathrm{CoO} \mathrm{NCs}$. The highest absorption peaks were observed at $212 \mathrm{~nm}$ for $\mathrm{CuO}, 243 \mathrm{~nm}$ for $\mathrm{ZnO}$ NPs, and at $212(\square 1)$ and $345 \mathrm{~nm}\left(\square_{2}\right)$ for CoO/ZnO NCs. The direct and indirect optical band gap for $\mathrm{ZnO}, \mathrm{CuO} \mathrm{NPs}$, and $\mathrm{CoO} / \mathrm{ZnO}$ NCs was found from Tauc relation [32] given in Eq. (6).

$$
\alpha h v=B\left(h v-E_{g}\right)^{\gamma}
$$

Here, $\square$ is the frequency of light, B is the band tailing parameter, $E_{g}$ is the optical band gap, and $\square$ is the optical index whose value is 2 and $1 / 2$ for indirect allows and direct allowed, respectively.

The indirect bandgap for $\mathrm{ZnO}, \mathrm{CuO} \mathrm{NPs}$, and $\mathrm{CoO} / \mathrm{ZnO}(0.3 / 0.7) \mathrm{NCs}$ was found to be 3.2, 2.7 , and $2.1 \mathrm{eV}$, respectively. It was observed that the electrical conductivity of $\mathrm{CoO} / \mathrm{ZnO} \mathrm{NCs}$ (lesser optical band gap) was found to be higher than $\mathrm{ZnO}$ and $\mathrm{CuO}$ NPs. 


\section{Computational study}

The theoretical study was carried out to investigate band structure, density of states (DOS), XRD (theoretical), Radial Distribution Function (RDF), and Brillouin zone paths for $\mathrm{CoO}$ and ZnO NPs (Figs. 11-12). Band structure shows the dependency of electronic states on the kvector and high symmetry vectors of the Brillouin zone. Band structure of $\mathrm{CoO}$ and $\mathrm{ZnO}$ NPs helps in qualitative analysis of the electronic structure and optical properties. Fig. 11(A), shows the electronic states of ZnO NPs. All the energies are related to the Fermi level. The symmetry point is denoted by $\mathrm{G}$. The maximum band gap observed in the case of $\mathrm{ZnO}$ NPs was $0.765 \mathrm{eV}$. Fig. 11(B), CASTEP density of states (DOS) represent smearing of different energy states and then plotting histogram for different k-points. The DOS provides characteristics information such as valence band (VB) width, energy band gap, and number and intensity of wave vectors to electron energies. The radial distribution function (RDF) was carried out by the Forcite module for finding the probability function, $\mathrm{g}(\mathrm{r})$ between $\mathrm{Zn}$ and $\mathrm{O}$ atoms for the distance (r). Fig. 11(C) shows RDF between $\mathrm{Zn}$ and $\mathrm{O}$ atoms. The maximum distance selected was $20 \mathrm{~A}^{0}$ and the interval was $0.01 \mathrm{~A}^{0}$. The $\mathrm{g}(\mathrm{r})$ was found to have a maximum up to $12 \mathrm{~A}^{0}$ after that it was almost constant. Fig. 11(D) shows the Forcite module for X-ray intensity versus $2 \square$. The highest intensity peak in theoretical XRD spectra was observed at $2 \square=36.4$ for ZnO NPs. Fig. 11 (E, G, and G) shows the 3D molecular plane, 3D molecular crystal structure showing reciprocal lattice, and Brillouin zone paths, respectively for $\mathrm{ZnO}$ NPs. Fig. 12(A), shows the electronic states of CoO NPs. All the energies are related to the Fermi level. The maximum band gap observed in the case of CoO NPs was $0.157 \mathrm{eV}$. Fig. 12(B), shows CASTEP density of states (DOS) and the histogram for different k-points. The radial distribution function (RDF) was carried out by the Forcite module for finding the probability function, $\mathrm{g}(\mathrm{r})$ between $\mathrm{Co}$ and $\mathrm{O}$ atoms for the distance (r). Fig. 12(C) shows RDF between $\mathrm{Co}$ and $\mathrm{O}$ atoms. The maximum distance selected was $20 \mathrm{~A}^{0}$ and the interval was 0.01 $\mathrm{A}^{0}$. The $\mathrm{g}(\mathrm{r})$ was found to have a maximum up to $14 \mathrm{~A}^{0}$ after that it was almost constant. Fig. 12(D) shows the Forcite module for X-ray intensity versus $2 \square$. The highest intensity peak in theoretical XRD spectra was observed at $2 \square=36.5$ and 42.4 for CoO NPs. Fig. 12 (E, G, and G) shows 3D molecular crystal structure showing reciprocal lattice and Brillouin zone paths (E), 3D molecular plane (F), Ball and stick model, respectively for CoO NPs.

\section{Conclusions:}


The cobalt doped $\mathrm{Zn}_{1-\mathrm{x}} \mathrm{Co}_{\mathrm{x}} \mathrm{O}$ NCs were prepared by sol-gel route. The effect of $\mathrm{CoO}$ concentration on $\mathrm{Zn}_{1-\mathrm{x}} \mathrm{Co}_{\mathrm{x}} \mathrm{O} \mathrm{NCs}$ was thoroughly investigated by UV-visible, FTIR, XRD, TEM, W-H plots, and VSM techniques. The experimental study was supported by the theoretical (DFT) study. The optical band gap energy (theoretical) was found lesser in $\mathrm{CoO}$ as compared to $\mathrm{ZnO}$ NPs. The Co-doped $\mathrm{ZnO}$ NCs were cubic phase as compared to the Wurtzite structure of $\mathrm{ZnO}$ NPs and $\mathrm{CoO}$ NPs has secondary phase. As the $\mathrm{CoO}$ NPs concentration was increased, the intensity of the peak increases and the width decreases. The micro strain peak broadening was observed using a W-H plot and the dislocation density was calculated for each NCs. The micro-strain and dislocation density decrease with increase in the $\mathrm{CoO}$ concentration. The grain size increases uniformly due to the incorporation of $\mathrm{CoO}$ in $\mathrm{ZnO}$ matrix. The particle size of the crystallites increases from 14.93 to $28.78 \mathrm{~nm}$ due to growth of NCs involving the Co ions. FTIR analysis confirms the formation of defect centers in the structure. TEM images reveal the formation of NPs cluster that may be due to magnetic dipole interaction between $\mathrm{ZnO}$ NPs. The magnetic properties like retentivity, coercivity, and saturation magnetization of NCs decreases while the particle size increases. The structural, electronic, magnetic, and optical properties of Co-doped $\mathrm{ZnO} N C s$ prove that $\mathrm{Zn}_{1-\mathrm{x}} \mathrm{Co}_{\mathrm{x}} \mathrm{O}$ nanocomposite will act as an efficient material for spintronic applications. 


\section{Reference:}

1. R. P. Feynmann, There's Plenty of Room at the Bottom, Engg. and Sci. 23, 22-36 (1960)

2. N. Taniguchi, On the Basic Concept of 'Nano-Technology, Proc. Intern. Conf. Prod. Eng. Tokyo, Part II, Japan Society of Precision Engg. (1974)

3. B. K. G. Theng, Formation and Properties of Clay-Polymer Complexes. (Elsevier, Burlington, 1979) pp. 77-85

4. B. Bhushan, Handbook of Nanotechnology, (Springer, 2007)

5. P. Moriarty, Nanostructured Materials, Rep. Prog. Phys. 64, 297-381 (2001). https://doi.org/10.1088/0034-4885/64/3/201

6. H. Gleiter, Nanostructured materials: basic concepts and microstructure. Acta Mater 48, 1-29 (2000) https://doi.org/10.1016/S1359-6454(99)00285-2

7. B. Martínez, A. Roig, E. Molins, Magnetic characterization of $\gamma-\mathrm{Fe}_{2} \mathrm{O}_{3}$ nanoparticles fabricated by aerosol pyrolysis. J. Appl. Phys. 83, 3256-3262 (1998) https://doi.org/10.1063/1.367093

8. W. Oswald, The world of Neglected Dimensions, (Dresden, 1915)

9. K. Kamiya, S. Sakka, Gypsum Lime 163, 23 (1979) https://doi.org/10.11451/mukimate1953.1979.243

10. H. Kumar, R. Rani, Rahul, A. Yadav, Rajni, Synthesis, characterization and influence of reduced Graphene Oxide (rGO) on the performance of mixed metal oxide nanocomposite as optoelectronic material and corrosion inhibitor, Chemical Data Collection 29, 100527 (2020) https://doi.org/10.1016/j.cdc.2020.100527

11. H. Kumar, A. Boora, A. Yadav, Rahul, Rajni, Polyaniline-metal oxide-nanocomposite as a nano-electronics, optoelectronics, heat resistance, and anti-corrosive material. Results Chem. 2, 100046 (2020). https://doi.org/10.1016/j.rechem.2020.100046

12. H. Kumar, Rajrani, Rahul, A. Yadav, Rajni, Synthesis, characterization, and influence of reduced Graphene Oxide (rGO) on the performance of mixed metal oxide nanocomposite as optoelectronic material and corrosion inhibitor. Chem Data Collect 29, 100527 (2020) https://doi.org/10.1016/j.cdc.2020.100527

13. H. Kumar, R. Sharma, A. Yadav, R. Kumari, Recent advancement made in the field of reduced graphene oxide-based nanocomposites used in the energy storage devices: A review. J. Energy Storage 33, 102032 (2021) https://doi.org/10.1016/j.est.2020.102032

14. R. Elilarassi, G. Chandrasekaran, Synthesis, Structural and Magnetic Characterization of Ni-Doped ZnO Diluted Magnetic Semiconductor. Am. J. Mater. Sci. 2, 46-50 (2012). https://doi.org/10.5923/j.materials.20120201.09

15. S. Udaykumar, V. Renuka, J. Chem. Pharmac. Res. 4, 1-6 (2012)

16. A. Mesaros, C. D. Ghitulica, M. Popa, Synthesis, structural and morphological characteristics, magnetic and optical properties of Co-doped $\mathrm{ZnO}$ nanoparticles. Ceram. Intern. 40, 2835-2846 (2014) https://doi.org/10.1016/j.ceramint.2013.10.030

17. H. P. Kulg, L.E. Alexander, X-ray Diffraction Procedure, $2^{\text {nd }}$ Ed., John Willey and Sons Inc. 9:687 (1974) 978-0-471-49369-3

18. G.K. Williamson, W.H. Hall, X-ray line broadening from filed aluminum and wolfram. Acta Metall. 1, 22-31 (1953) https://doi.org/10.1016/0001-6160(53)90006-6

19. F.U. Jianlong, J. of Alloys Comp. 558, 212 (2013).

20. L.B. Duan, G. H. Rao, J. Yu, Y.C. Wang, Ferromagnetism of lightly Co-doped ZnO nanoparticles. Solid State Commun. 145, 525-528 (2008) https://doi.org/10.1016/j.ssc.2008.01.0Edn. Oxford: Clare don Press. 
21. R. Elilarassi, G. Chandrasekaran, Microstructural and photoluminescence properties of Co-doped $\mathrm{ZnO}$ films fabricated using a simple solution growth method Mat. Sci. Semicond. Proces. 14(2),179-183 (2011) https://doi.org/10.1016/j.mssp.2010.11.001

22. M. Sheik, M. Badhusha, Der Pharma Chemica 8, 78 (2016)

23. Y. Caglar, Sol-gel derived nanostructure undoped and cobalt doped $\mathrm{ZnO}$ : Structural, optical and electrical studies. J. Alloys Compd. 560, 181-188 (2013) https://doi.org/10.1016/j.jallcom.2013.01.080

24. F. Ahmed, S. Kumar, N. Arshi, M.S. Anwar, B.H. Koo, C.G. Lee, Doping effects of $\mathrm{Co}^{2+}$ ions on structural and magnetic properties of $\mathrm{ZnO}$ nanoparticles Microelectronic Engg. 89, 129 (2012) https://doi.org/10.1016/j.mee.2011.03.149

25. L.H. Van, M.H. Hong, J. Ding, Structural and magnetic property of Co-doped-ZnO thin films prepared by pulsed laser deposition. J. Alloys Compd. 449, 207-209 (2008) https://doi.org/10.1016/j.jallcom.2006.02.114

26. L. Estepa, M. Daudon, Contribution of Fourier transform infrared spectroscopy to the identification of urinary stones and kidney crystal deposits. Biospectroscopy 3, 347-369 (1997) https://doi.org/10.1002/(SICI)1520-6343(1997)3:5<347::AIDBSPY3> 3.0. CO;2-\#

27. S.H. Wu, D.H. Chen, Synthesis and characterization of nickel nanoparticles by hydrazine reduction in ethylene glycol. J. Colloid Interface Sci. 259, 282-286 (2003) https://doi.org/10.1016/S0021-9797(02)00135-2

28. R. He, R.K. Hocking, T. Tsuzuki, Co-doped ZnO nanopowders: Location of

29. cobalt and reduction in photocatalytic activity. Mater. Chem. Phys. 132, 1035-1040 (2012) https://doi.org/10.1016/j.matchemphys.2011.12.061

P. Li, S. Wang, J. Li, Y. Wei, Structural and optical properties of Co-doped ZnO nanocrystallites prepared by a one-step solution route. J. Lumin. 132, 220-225 (2012). https://doi.org/10.1016/j.jlumin.2011.08.019

30. S. Wang, P. Li, H. Liu, The structure and optical properties of $\mathrm{ZnO}$ nanocrystals dependence on Co-doping levels. J. Alloys Compd. 505, 362-366 (2010)

31. S. Ghoshal, P.S.A. Kumar, Process-dependent magnetic properties of Co-doped $\mathrm{ZnO}$ in bulk and thin-film form. J. Magnet. Mag. Mat. 320(12), 93 (2008) 10.1016/j.jmmm.2008.02.174

32. N.F. Mott, E.A. Davies, Electronic Processes in Non-Crystalline Materials. $2^{\text {nd }}$ Edn. (Oxford, Clare don Press, 1979) pp. 87-115 
Figures
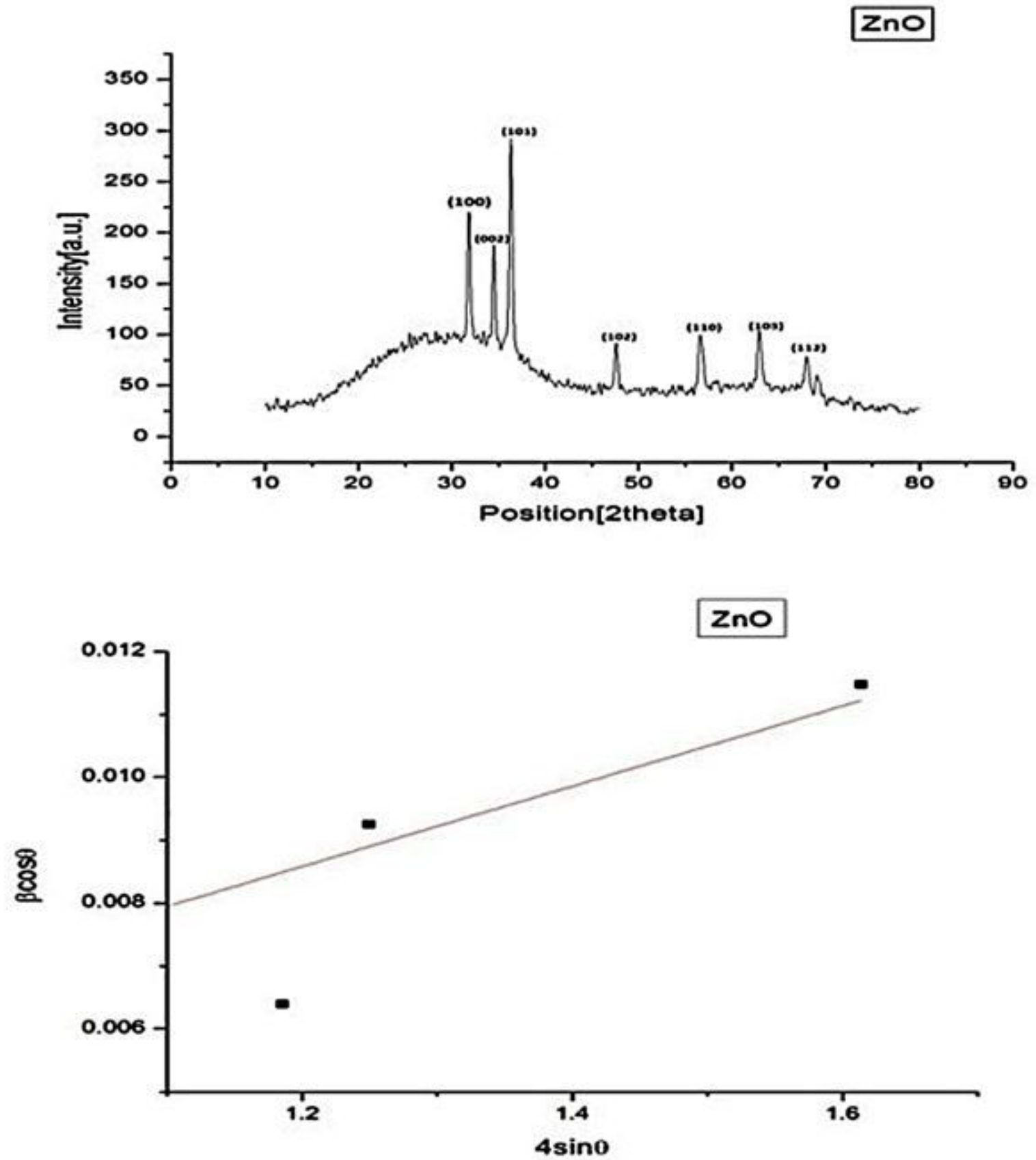

Figure 1

(a) XRD pattern and (b) W-H plot of $\mathrm{ZnO}$ nanoparticles. 

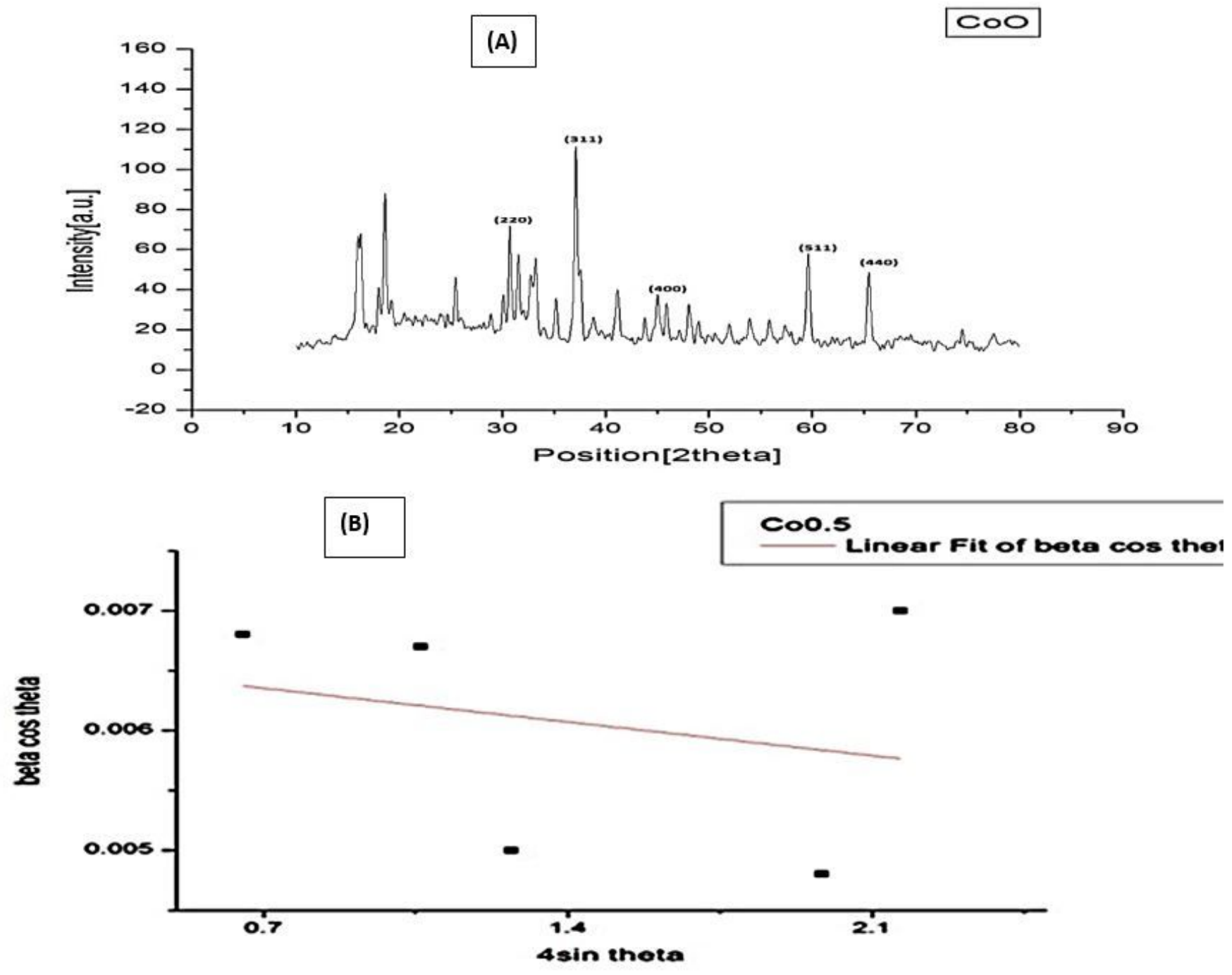

Figure 2

XRD pattern of $\mathrm{CoO}$ nanoparticle (A), and $\mathrm{W}-\mathrm{H}$ plot of $\mathrm{CoO}$ nanoparticles (B). 

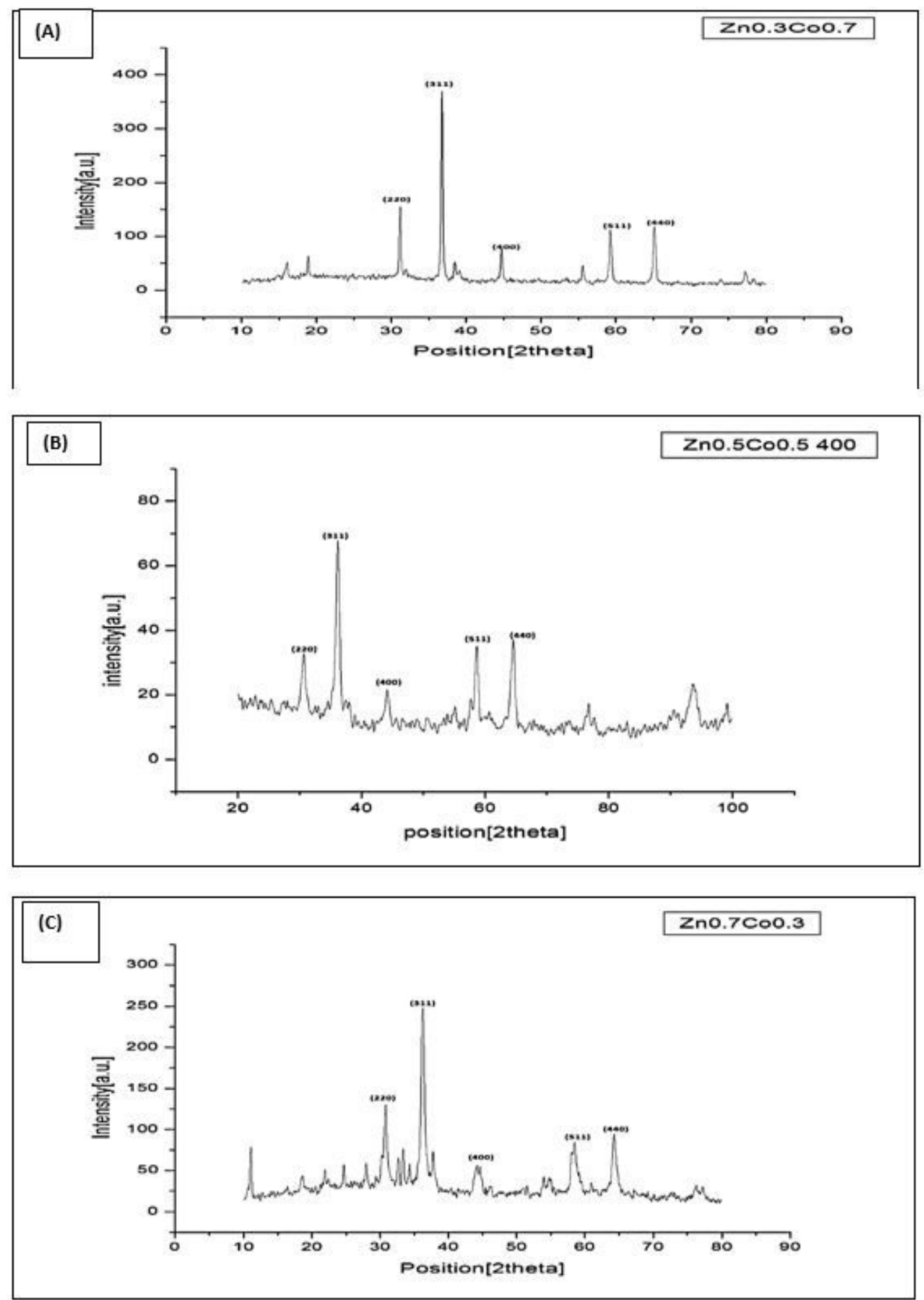

Figure 3

XRD pattern of (A)Zn0.3CoO0.7 (B) Zn0.5 CoO0.5 (C) Zn0.7 CoO0.3 nanocomposites. 

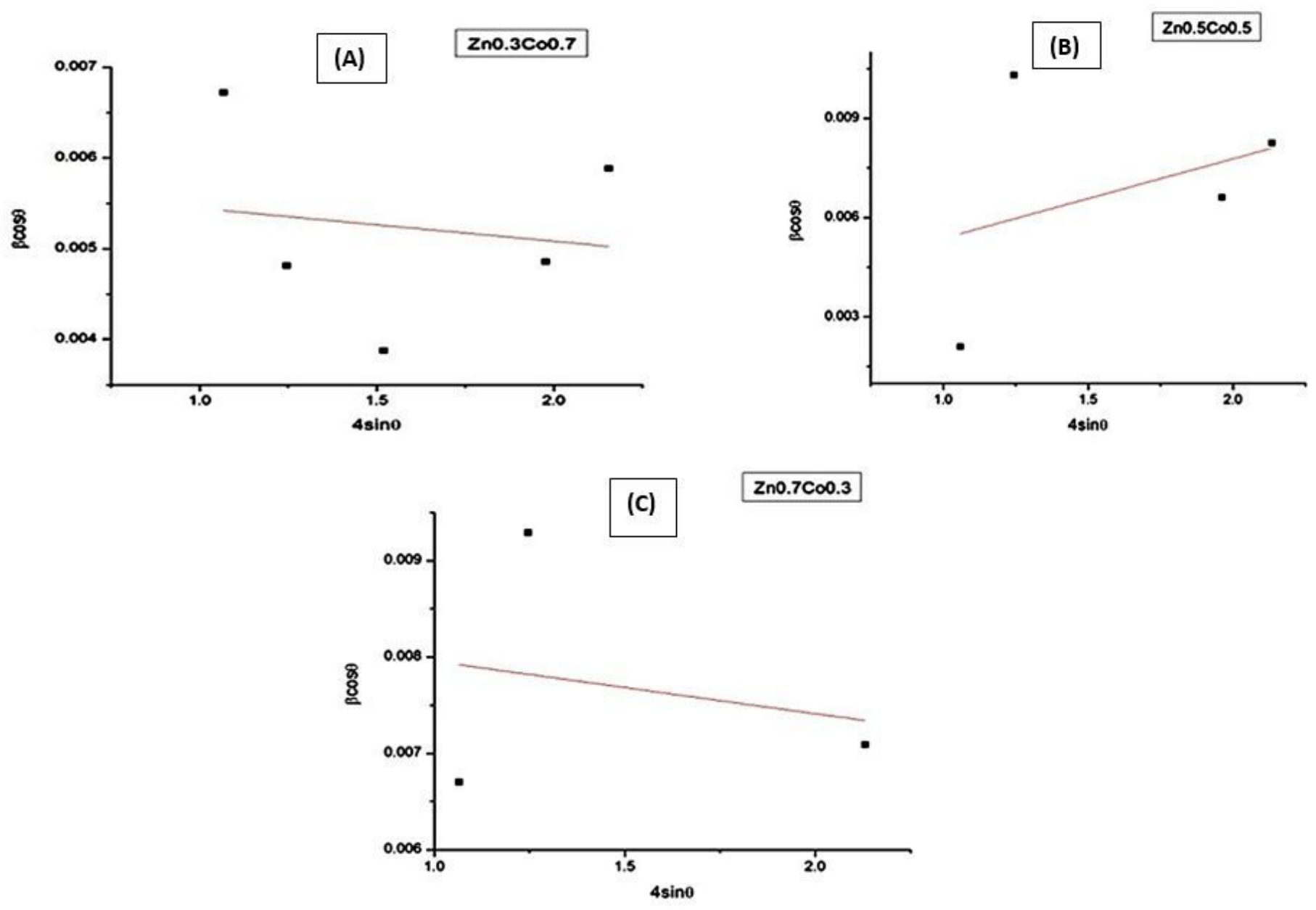

Figure 4

W-H plot of Zn0.3 CoO0.7 (A), Zn0.5 CoO0.5 (B), and Zn0.7 CoO0.3 nanocomposites (C). 

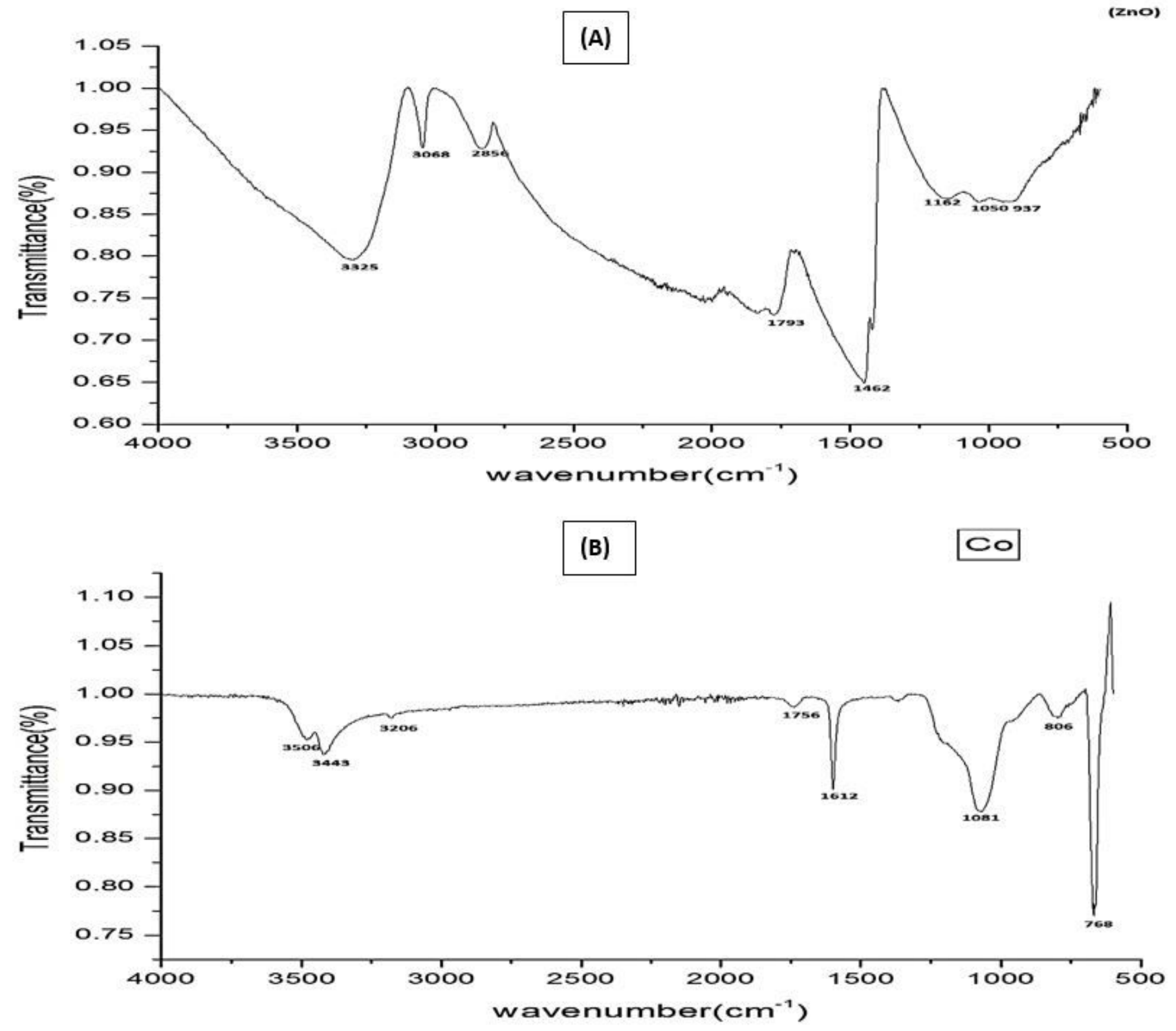

Figure 5

FTIR spectra of ZnO nanoparticles (A) and $\mathrm{CoO}$ nanoparticles (B). 

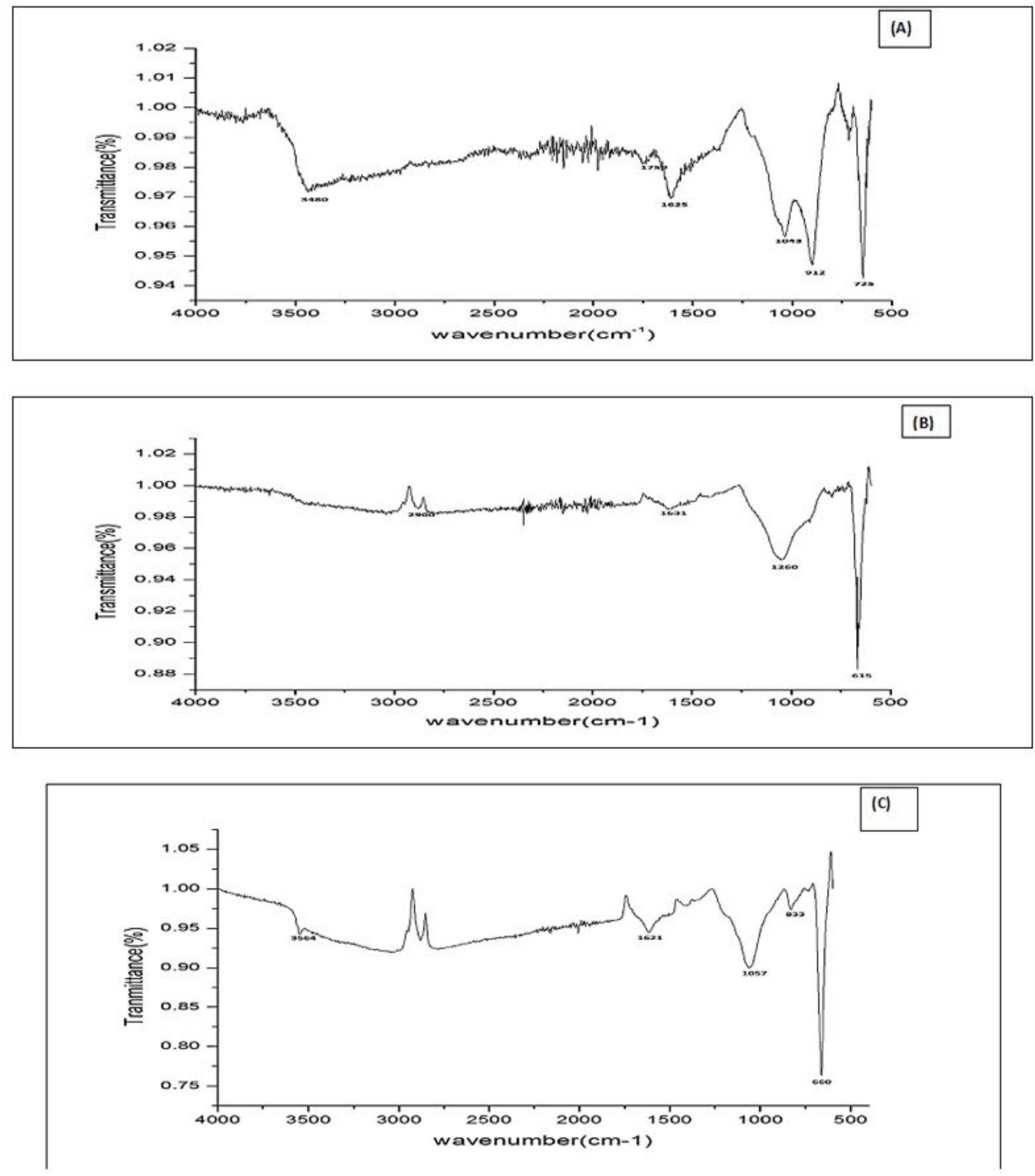

Figure 6

FTIR spectra of Zn0.7 CoO0.3 (A), Zn0.5 CoO0.5 (B), and Zn0.3CoO0.7 nanocomposites (C). 

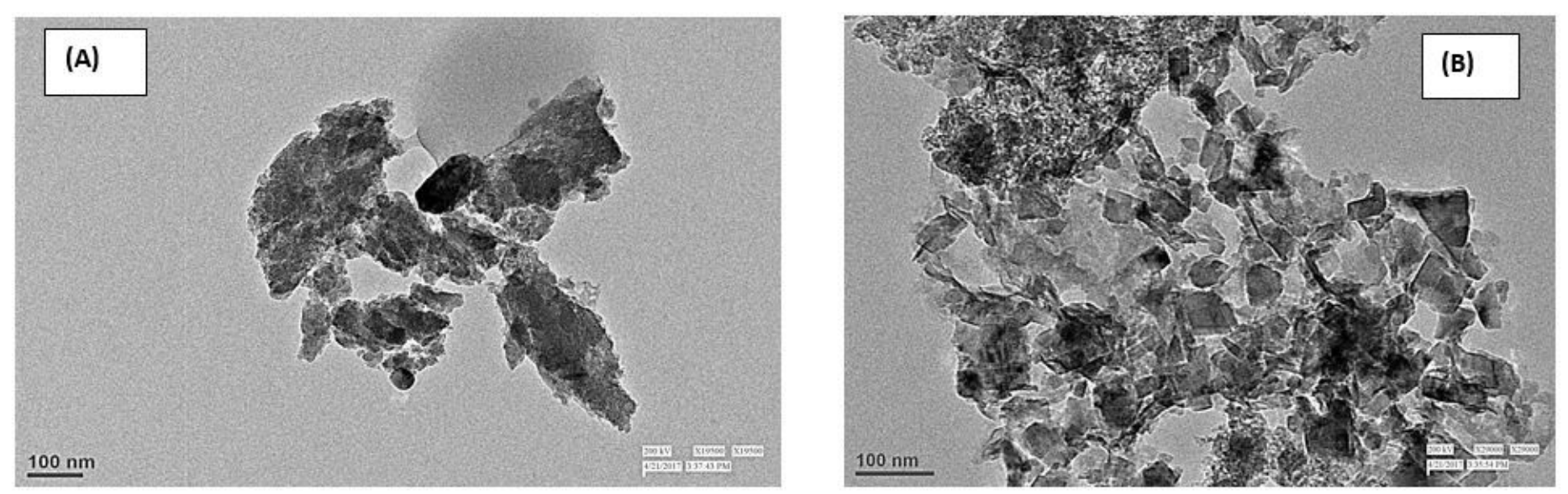

Figure 7

TEM images of (A) ZnO and $\mathrm{CoO}$ nanoparticles (B). 

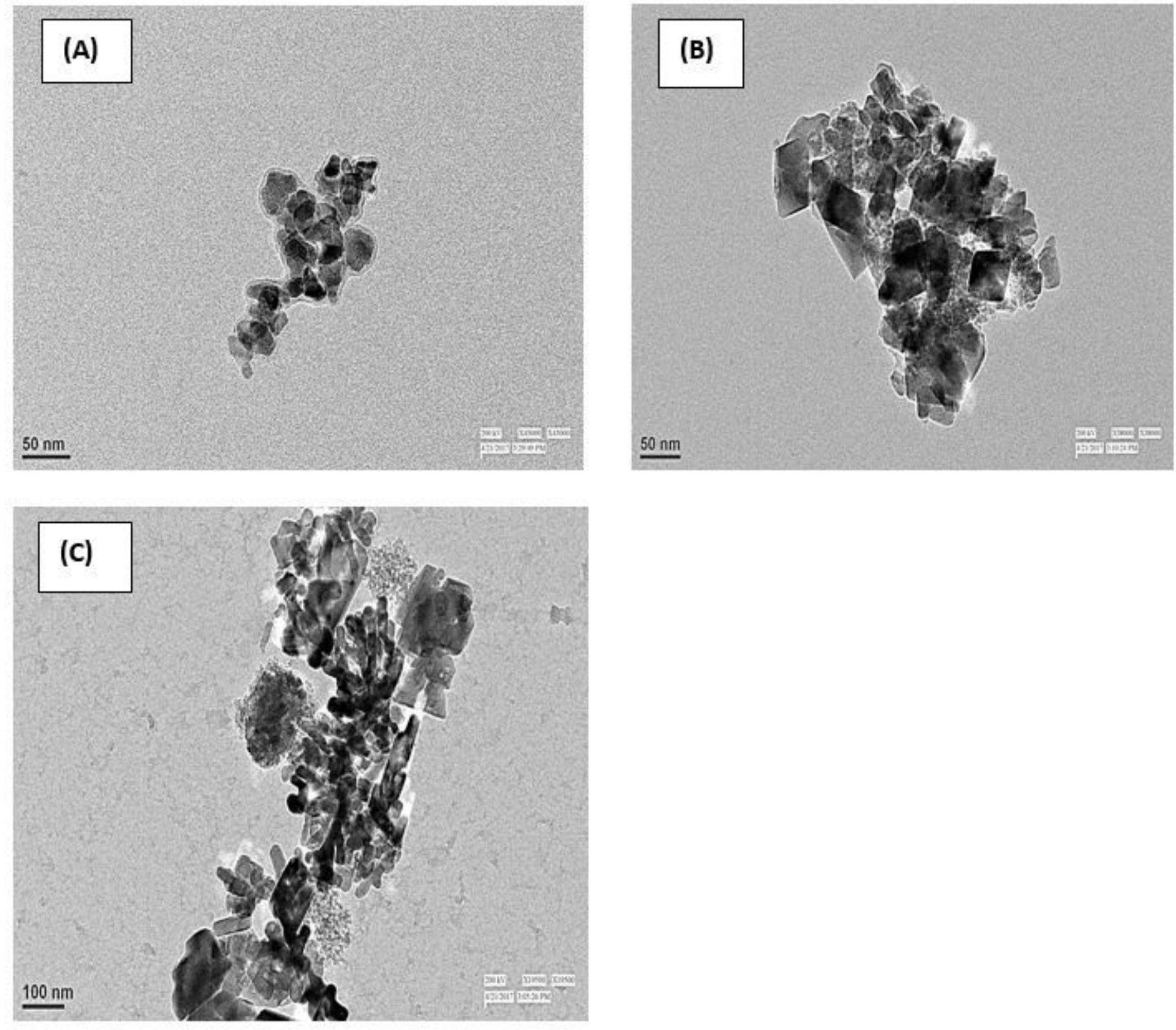

Figure 8

TEM Images of ZnO0.7CoO0.3 (A) ZnO0.5 CoO0.5 (B) Zn00.3 CoO0.7 (C) nanocomposites. 

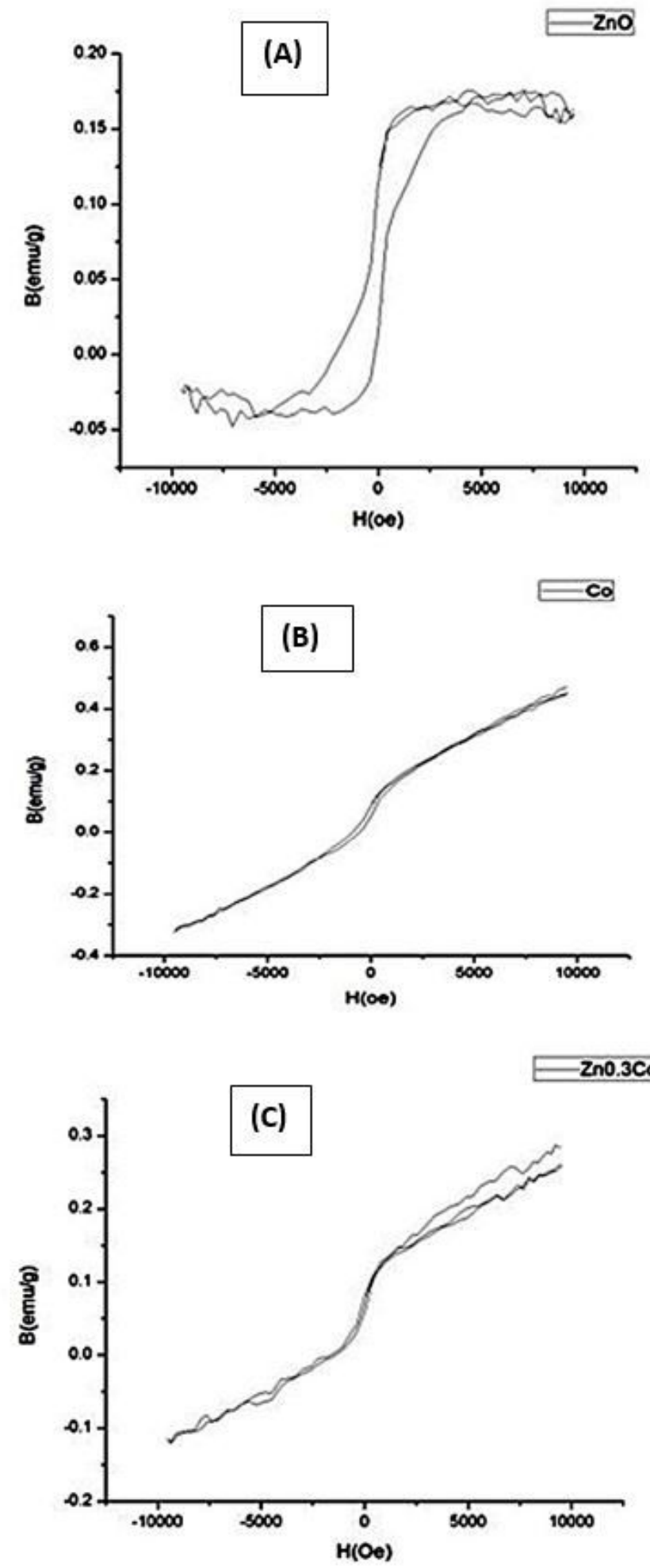

Figure 9

$\mathrm{M}-\mathrm{H}$ curves of $\mathrm{ZnO}$ nanoparticles (A), CoO nanoparticles (B), and $\mathrm{ZnO0.3} \mathrm{CoO0.7} \mathrm{nanocomposites} \mathrm{(C).}$ 

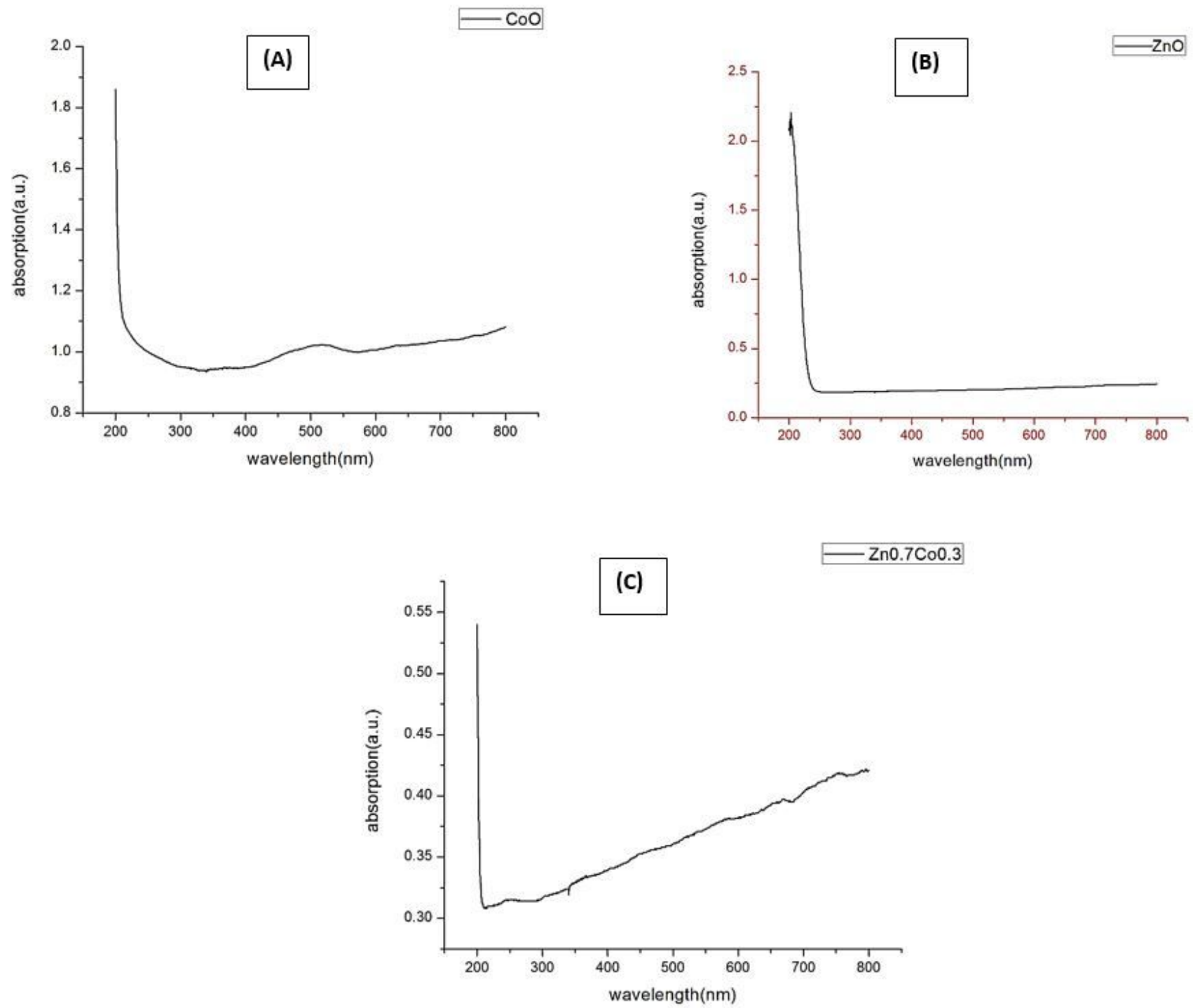

Figure 10

UV-visible absorption spectra of $\mathrm{CoO}(\mathrm{A})$, and $\mathrm{ZnO}$ nanoparticles (B) and $\mathrm{ZnO} / \mathrm{CoO}$ nanocomposites (C). 

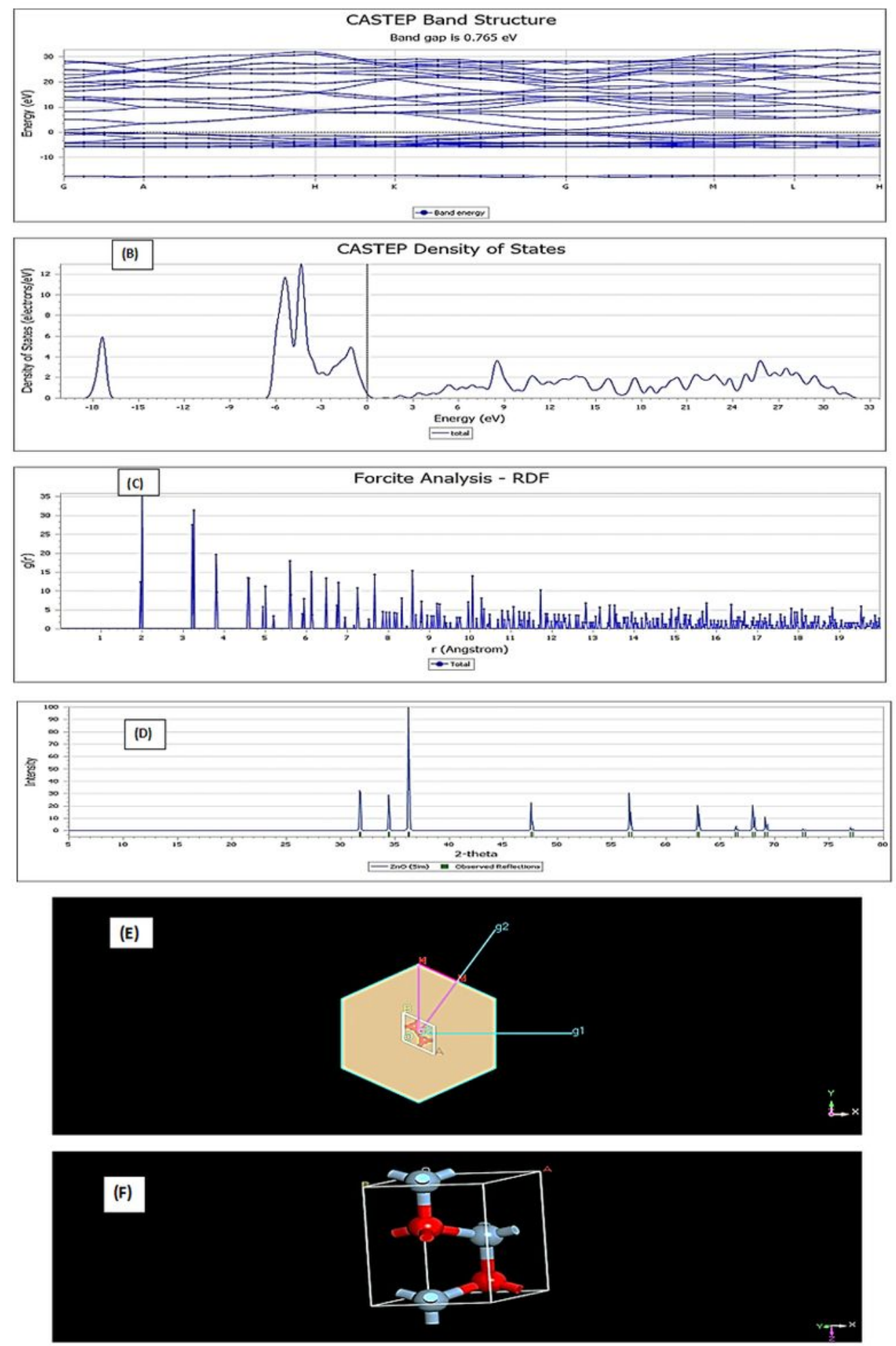

\section{Figure 11}

CASTEP band structure (A), CASTEP Density of States (B), Forcite radial distribution function (C), XRD (D), 3D molecular plane (E), 3D molecular crystal structure showing reciprocal lattice and Brillouin zone paths (F) of ZnO nanoparticles obtained from Materials Studio 2017 software. 

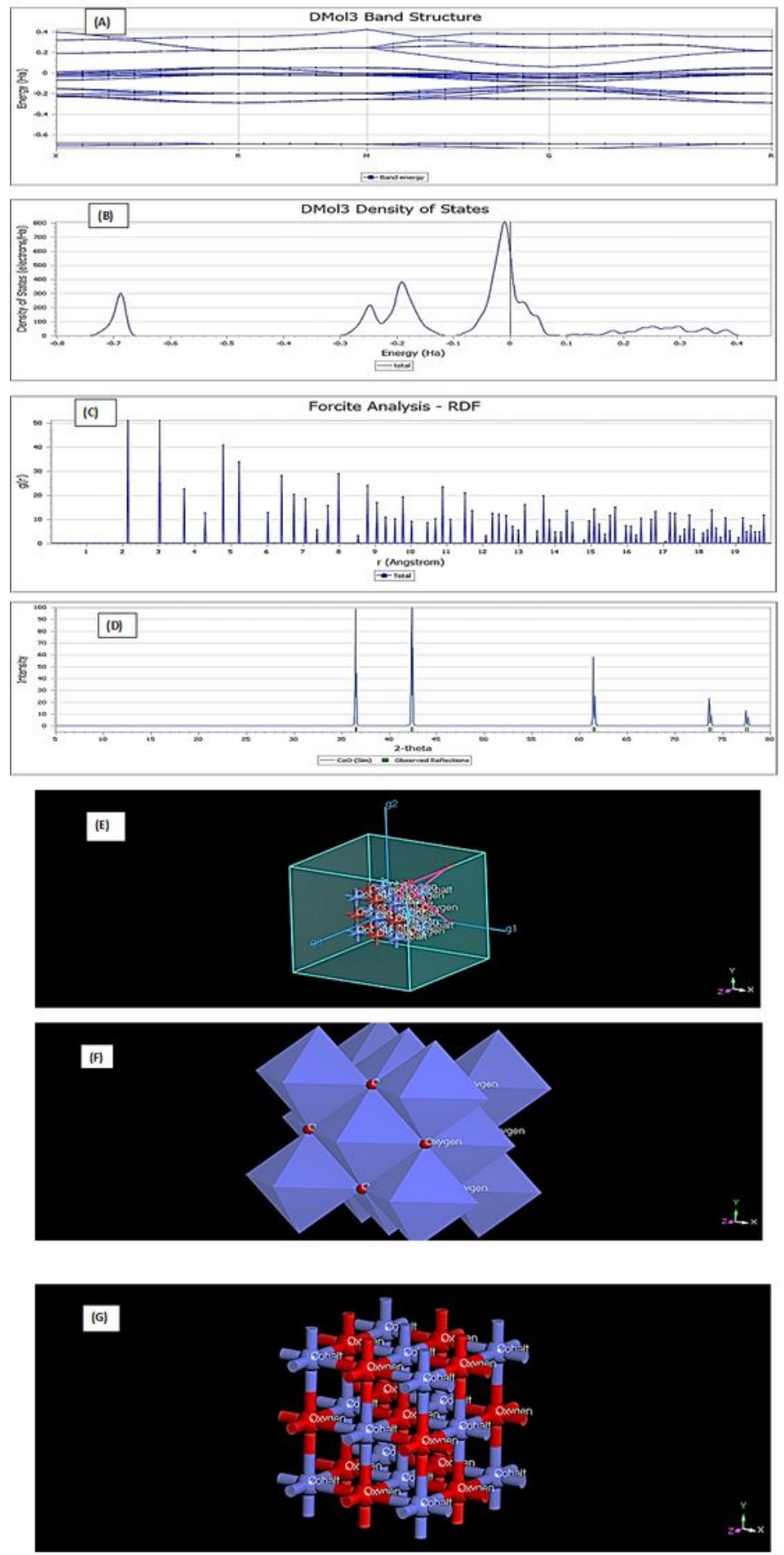

Figure 12

Dmol3 band structure (A), DMol3 Density of States (B), Forcite radial distribution function (C), XRD (D), 3D molecular crystal structure showing reciprocal lattice and Brillouin zone paths (E), 3D molecular plane (F), Ball and stick model (G) of CoO nanoparticles obtained from Materials Studio 2017 software.

\section{Supplementary Files}


This is a list of supplementary files associated with this preprint. Click to download.

- GraphicalAbstract.docx 